\title{
Post abortion care: experience of the gynecological and obstetrical service of Treichville university hospital center, Abidjan-Cote D'ivoire
}

\section{Dia Jean Marc*, Bohoussou Eric, Yao Ignace, Oyéladé Mouhideen, Okon Gerard, Guié Yeret Privat, Anongba Simplice}

Department of Obstetrics and Gynecology, Treichville Teaching Hospital, Abidjan-Côte d'Ivoire

Received: 14 November 2016

Accepted: 03 December 2016

\section{*Correspondence:}

Dr. Dia Jean Marc,

E-mail: jmlaminedia@yahoo.fr

Copyright: $\odot$ the author(s), publisher and licensee Medip Academy. This is an open-access article distributed under the terms of the Creative Commons Attribution Non-Commercial License, which permits unrestricted non-commercial use, distribution, and reproduction in any medium, provided the original work is properly cited.

\section{ABSTRACT}

Background: The objectives of our study were to determine the sociodemographic characteristics of the patients received in our service for abortion and to describe the Post Abortion Cares (PAC) that have been administered since the 2014 reorganization.

Methods: This was a descriptive and prospective study over 12 months taking into account patients admitted to our department for abortion.

Results: The frequency of abortions was $24 \%$. The majority of patients were less than 25 years old $(84.95 \%)$ and single $(74.33 \%)$ had a low level of study $(71.68 \%)$, an induced abortion history $(73.75 \%)$ and a notion of contraceptive use (58\%). On admission $15.48 \%$ of abortions were complicated. Patients mostly received, during their stay, abortion emergency cares (71.68\%), contraception (81.25\%) and HIV test $(90.26 \%)$. They also benefited at 6 weeks from the cervical cancer screening $(78.57 \%)$.

Conclusions: The reorganization of the practice of abortion care permitted us to have the expected results.

Keywords: Abortion, Contraception, Post abortion care

\section{INTRODUCTION}

The abortions expose to serious complications from which Africa is suffering: $14 \%$ of maternal deaths in Africa are due to abortions. ${ }^{1}$ To fight against this phenomenon, the World Health Organization (WHO) insists on the promotion of Post-Abortion Care (PAC) concept, which recommends integrating to abortion classic emergency care for patients, prevention services of unwanted pregnancies (family planning) and HIV infection. In our department since 2014, we reorganized the care giving circuit of the PAC to make the services available at all times to better meet the recommended standards.

This study aims to determine sociodemographic characteristics of the patients received for abortion in our service and describe the PACs that have been administered to them since that reorganization.

\section{METHODS}

This was a prospective and descriptive study conducted from $1^{\text {st }}$ of August 2014 to $31^{\text {st }}$ of July 2015 (12 months) on patients who have been admitted for abortion to the gynecological emergency service of CHU Treichville (University Hospital).

All patients in whom the examination confirmed the diagnosis of abortion and who benefited from the PAC during this period were included in the study.

Data collection was done using a listing of individual survey from the records of abortions, gynecological 
emergencies, operating theater, operative reports and medical observation records.

For each patient, we studied the epidemiological and diagnostic characteristics, as well as the administered PAC.

\section{The reorganization of our abortions care services}

Before August 2014, patients admitted for abortion in our service were recorded in a common register for all gynecological emergency admissions, making follow-up difficult. They benefited from the Abortion Emergency Care (AEC) without HIV testing or systematic prescription of contraceptives before their release. An appointment for check- up examination was due within two weeks, during which testing for HIV and family planning (FP) services were offered. But we found that few patients met these appointments, making inefficient our PAC circuit. Also, our service is not computerized and the recording in same register all the patients received in emergency (abortions, other emergency cases) did not permit us to follow the entire patient during the check-up visit.

Since August 1, 2014, we reorganized our circuit, so that all services for PAC are systematically offered to all patients admitted for abortion. Thus, all patients are now stored in a register meant only for the PAC, making easy their follow-up. All the stages of the PAC systematically included counseling. HIV testing and contraceptives are readily available in the gynecological emergency unit, so that during the stay of the patient, the cares offered to her integrate Abortion Emergency Care (AEC), HIV testing and family planning (FP).

In addition, at the release of the patient, she is given a week appointment for check-up then 6 weeks for cervical cancer screening using visual inspection with acetic acid (VIA).

\section{RESULTS}

\section{Epidemiological characteristics}

\section{Frequency of abortions}

During the study period, 942 patients were admitted to gynecological emergency unit among which 226 (24\%) for abortion. These abortions were spontaneous in 66 patients $(29.2 \%)$ and induced in 160 patients $(70.8 \%)$.

Table 1: Distribution of patients according to their socio-demographic characteristics.

\begin{tabular}{|c|c|c|c|c|c|c|}
\hline \multirow[t]{2}{*}{ Characteristics } & \multicolumn{2}{|c|}{ Spontaneous abortions } & \multicolumn{2}{|c|}{ Induced abortions } & \multicolumn{2}{|c|}{ Total } \\
\hline & $\mathbf{N}$ & $\%$ & $\mathbf{N}$ & $\%$ & $\mathbf{N}$ & $\%$ \\
\hline \multicolumn{7}{|l|}{ Age (years) } \\
\hline$<18$ & 31 & 46.96 & 63 & 39.18 & 94 & 41.59 \\
\hline $19-25$ & 12 & 18.20 & 86 & 56.75 & 98 & 43.36 \\
\hline$>25$ & 23 & 34.84 & 11 & 06.08 & 34 & 15.05 \\
\hline Total & 66 & 100.00 & 160 & 100.00 & 226 & 100.00 \\
\hline \multicolumn{7}{|l|}{ Parity } \\
\hline 0 & 24 & 36.36 & 43 & 26.87 & 67 & 29.64 \\
\hline $1-2$ & 23 & 34.84 & 96 & 60.00 & 119 & 52.64 \\
\hline$\geq 3$ & 19 & 28.78 & 21 & 13.12 & 40 & 17.69 \\
\hline Total & 66 & 100.00 & 160 & 100.00 & 226 & 100.00 \\
\hline \multicolumn{7}{|l|}{ Level of study } \\
\hline None & 11 & 16.67 & 31 & 19.38 & 42 & 18.58 \\
\hline Primary & 25 & 37.88 & 95 & 59.38 & 120 & 53.10 \\
\hline Secondary & 22 & 33.33 & 30 & 18.75 & 52 & 23.00 \\
\hline Superior & 8 & 12.12 & 4 & 02.50 & 12 & 05.15 \\
\hline Total & 66 & 100.00 & 160 & 100.00 & 226 & 100.00 \\
\hline \multicolumn{7}{|l|}{ Marital status } \\
\hline Single & 15 & 22.73 & 153 & 95.62 & 168 & 74.33 \\
\hline Maried & 51 & 77.27 & 7 & 04.38 & 58 & 25.67 \\
\hline Total & 66 & 100.00 & 160 & 100.00 & 226 & 100.00 \\
\hline
\end{tabular}


Socio-demographic characteristics (Table 1)

Patients were aged less than 25 years in $84.95 \%$ of cases (192 patients) and a low level of education (no schooling or primary) in $71.68 \%$ of cases (162 patients). In the 160 patients who had induced abortions, 126 had a low educational level (78.75\%) and 117 had already had a child $(73.1 \%)$.

Among the 168 single patients, 153 had induced abortions $91.1 \%$ ).

Table 2: Distribution of patients according to their gynecological history.

\begin{tabular}{|c|c|c|c|c|c|c|}
\hline \multirow[t]{2}{*}{ Characteristics } & \multicolumn{2}{|c|}{ Spontaneous abortions (SA) } & \multicolumn{2}{|c|}{ Induced abortions (IA) } & \multicolumn{2}{|c|}{ Total } \\
\hline & $\mathbf{N}$ & $\%$ & $\mathbf{N}$ & $\%$ & $\mathbf{N}$ & $\%$ \\
\hline \multicolumn{7}{|l|}{ I A history } \\
\hline Yes & 15 & 22.73 & 118 & 73.75 & 133 & 58.85 \\
\hline No & 51 & 77.27 & 42 & 26.25 & 93 & 41.15 \\
\hline Total & 66 & 100.00 & 160 & 100.00 & 226 & 100.00 \\
\hline \multicolumn{7}{|l|}{ S A history } \\
\hline Yes & 12 & 18.18 & 72 & 45.00 & 84 & 37.17 \\
\hline No & 54 & 81.82 & 88 & 55.00 & 142 & 62.83 \\
\hline Total & 66 & 100.00 & 160 & 100.00 & 226 & 100.00 \\
\hline \multicolumn{7}{|c|}{ Contraceptive history } \\
\hline Yes & 35 & 53.00 & 96 & 60.00 & 131 & 58.00 \\
\hline No & 31 & 47.00 & 64 & 40.00 & 95 & 42.00 \\
\hline Total & 66 & 100.00 & 160 & 100.00 & 226 & 100.00 \\
\hline
\end{tabular}

Table 3: Distribution of patients as clinically indicated.

\begin{tabular}{|c|c|c|}
\hline Clinical characteristics & $\mathbf{N}$ & $\%$ \\
\hline \multicolumn{3}{|l|}{ Uncomplicated abortions } \\
\hline Complete abortions & & 28.32 \\
\hline Incomplete abortions & & 56.19 \\
\hline \multicolumn{3}{|l|}{ Complicated abortions } \\
\hline Incomplete haemorrhage abortions & 22 & 09.73 \\
\hline Incomplete septic abortions & 9 & 03.98 \\
\hline Perforation uterine & 4 & 01.77 \\
\hline Total & 226 & 100.00 \\
\hline
\end{tabular}

\section{The gynecological history of the patients (Table 2)}

\section{The clinical characteristics of abortion}

The age of pregnancy

The age of the pregnancies during abortion was inferior to 12 weeks in $85 \%$ of cases (193 patients).

\section{The clinical picture (Table 3)}

The abortions were incomplete in 158 patients $(69.91 \%)$, and complicated in 35 patients $(15.48 \%)$.

\section{The post-abortion care (PAC)}

Abortion emergency care (AEC) (Table 4)
The AEC were realized in 162 patients including 158 uterine evacuations for incomplete abortions, and 4 laparotomies for surgical abdomen pictures ( 2 cases of hysterography and 2 cases of hysterectomy for uterine perforation).

Table 4: Distribution of patients according to uterine evacuation technique used.

\begin{tabular}{|lll|}
\hline Uterine evacuation & N & $\%$ \\
\hline MVA & 117 & 74.05 \\
\hline Digital dissection & 26 & 16.45 \\
\hline Misoprostol & 15 & 09.50 \\
\hline Total & 158 & 100.00 \\
\hline
\end{tabular}

MVA: manual vacuum aspiration

Some patients have also received additional drug treatments: antibiotics (99.3\%), uterotonics (98.2\%), analgesics $(67.7 \%)$, blood transfusions (14.6\%). During the management of 226 emergency patients, two maternal deaths were recorded $(0.88 \%)$, including one, by hemorrhagic shock after uterine evacuation and the other by septic shock in the post-operative hysterectomy.

\section{HIV testing}

During their stay in the hospital, HIV testing was realized in 204 patients ignorant of their status. This test permitted to screen 42 HIV positive patients $(20.59 \%)$. 


\section{Family planning (FP) (Table 5)}

In the 224 patients who survived after the AEC, 182 $(81.25 \%)$ agreed to start a contraceptive method (Table 4$)$ including 172 acceptances during their stay and 10 during the one-week appointment visit.

Table 5: Distribution of patients according to the chosen method of contraception.

\begin{tabular}{|lll|}
\hline Contraceptive choices & N & $\%$ \\
\hline DIU & 82 & 45.05 \\
\hline Implant & 51 & 28.02 \\
\hline Injection & 30 & 16.49 \\
\hline Pilules & 19 & 10.45 \\
\hline Total & 182 & 100.00 \\
\hline
\end{tabular}

During the follow-up appointment, all the patients who chose a contraceptive method were satisfied with their choice and promised to continue this method on more than 6 months. 42 patients refused a contraceptive method including 25 for religious constraints and 17 for refusal of spouse.

\section{Cervical cancer screening}

In the 224 patients who survived after the AEC, 176 patients $(78.57 \%)$ respected their 6 week appointment visit, during which they all benefited from cervical cancer screening. There were 5 positive results: all of them were low grade lesions $(2.92 \%)$.

\section{DISCUSSION}

\section{Epidemiological characteristics}

\section{Frequency of abortions}

During the study period, abortions represented $24 \%$ of our admissions to gynecological emergencies, and were essentially dominated by induced abortions (70.8\%). Previous studies have already highlighted the high rate of induced abortions in our country. ${ }^{2-4}$ This phenomenon is also widespread across Africa and has even grown from 5.6 million in 2003 to 6.4 million in $2008 .^{5}$

\section{Socio-demographic characteristics}

The majority of our patients were under 25 years old $(84.95 \%)$ and still had ahead a long period of genital activity exposing them to unwanted pregnancies. Also we find that the majority of women who had induced abortion were under 25 years, in contrast to older women in whom spontaneous abortions were predominant. Among these young patients, the rate of adolescents was important: $41.59 \%$.

The extent of teenage pregnancies is well known in our developing countries due to a low rate of contraceptive prevalence among these girls. ${ }^{6-8}$ The low rate of contraceptive used among adolescents in our country, is linked to such several factors as early marriage, taboo, lack of access to contraceptives.

In addition, in the 160 patients who had induced abortion, $117(73.1 \%)$ had already had a child. These patients had therefore already had contact with our health reproduction structures in previous pregnancies and should have been well sensitized on the prevention of induced abortions, through contraceptive methods.

Moreover, the majority of women in our study population were single $(74.33 \%)$ among whom induced abortion prevailed $(91.1 \%)$. In Africa the prevalence of induced abortions among unmarried women has also been reported by some authors. ${ }^{2,9}$ This trend may be explained by the persistence of cultural and religious considerations condemning pregnancies among unmarried women.

Regarding the educational level, it was low in most of our patients $(71.68 \%)$. The majority of induced abortions were found in patients with a low educational level (78.75\%). Elsewhere, some authors instead, found a prevalence of induced abortions among educated patients. They went so far to argue that the higher the level of study, the higher the probability of induced abortion increases. $^{2,4}$

These findings should permit us to encourage women of a low education study to choose contraceptives with both long durations of action and less constraint in treatment observance.

\section{The gynecological history of the patients}

Of the 160 patients who had induced abortions, the majority reported, on the one hand, to have already practiced an induced abortion $(73.75 \%)$ and on the other hand, they have used a contraceptive method (60\%), in the past. The findings reveal that after an induced abortion, if the patient is not under contraceptive, she will be exposed to another unwanted pregnancy. Secondly during the prescription of a contraceptive method, if the counseling is not well explained, the woman is likely not to correctly follow the treatment and consequently she is always exposed to an unwanted pregnancy. These findings justify the current reorganization of our practice of the PAC by offering a contraceptive method, after a good counseling, to the patients during their stay for the abortion emergency cares.

\section{The clinical characteristics on admission}

The abortions in our series have been recorded in pregnancies less than 12 weeks in $85 \%$ of cases (193 patients). These abortions were incomplete in $69.91 \%$ of cases (158 patients) and complicated in 15.48\% (35 patients). The main complications were bleeding $(9.73 \%)$, infections $(3.98 \%)$, and uterine perforations 
(1.77\%). The complications of induced abortions are frequent in our countries because abortion is not legalized there, but is often practiced in unsafe contexts. ${ }^{2,5}$

\section{PAC}

The AEC were realized free of charge in 162 patients and uterine evacuation with MVA has been the most used technique $(74.05 \%)$. This practice is recommended and popularized today to reduce the management delay and the length of hospital stay. ${ }^{10-12}$ All our doctors who treat the patients during emergencies have received training on the practice of MVA. We used also in some cases laparotomy and medicated treatments (antibiotics, uterotonics, analgesic and blood transfusion). Moreover, during their stay, HIV test was freely performed in 204 patients who did not know their status and permitted to detect 20,59\% of HIV-positive, who were immediately directed to management services. As for the FP, the majority of our patients $(81.25 \%)$ accepted a contraceptive method through a well conducted counseling and the availability of contraceptives at reduced costs. The low socio-demographic profile of our patients takes us to promote contraceptives with long duration action. Mayi and Zaidi had the same attitude, giving priority to contraceptives with long duration action in their practice on the PAC on patients with low sociodemographic status. ${ }^{9,13}$ Finally, the screening of cervical cancer was freely performed in all patients (176 patients or $78.57 \%$ ) who fulfilled their 6 weeks consultation. It allowed us to screen 5 positive results; all of them were low grade lesions $(2.92 \%)$. They were all immediately treated through cryotherapy. In our countries where cervical cancer is widespread, there is no mass screening campaign. So we have to take every opportunity where the women are in contact with our service to propose them screening which has become free of charge together with the treatment of cervical precancerous lesions.

\section{CONCLUSION}

This study permitted us to find that abortions are frequent in our service, affecting a population of low socioeconomic level. In most cases, the patients had a history of abortion. The reorganization of the PAC in our service allowed us to have expected results: abortion emergency care, family planning, HIV testing and cervical cancer were performed in the majority of patients. We recommend the widespread of this practice in all the hospitals around our country.

Funding: No funding sources

Conflict of interest: None declared

Ethical approval: The study was approved by the Institutional Ethics Committee

\section{REFERENCES}

1. World Health Organization. Unsafe Abortion: Global and regional estimates of the incidence of unsafe abortion and associated mortality in 2008, six ed., Geneva: WHO, 2011.

2. Vroh JB, Tiembre I, Attoh-Toure H, Kouadio DE, Kouakou L, Coulibaly L. Epidemiology of induced abortion in Côte d'Ivoire. Sante Publique. 2012;24(Spec No):67-76.

3. Desgrées du lou A, Msellati P, Viho I, Welffens-Ekra C. The Use of Induced Abortion in Abidjan: A Possible Cause of the Fertility Decline? In: population. 1999;54(3):427-46.

4. Guillaume A, Desgrées du Lou A. Fertility regulation among women in Abidjan, Côte d'Ivoire: contraception, abortion or both? International family planning perspectives. 2002;28(3):159-66.

5. Sedgh G. Induced abortion: incidence and trends worldwide from 1995 to 2008. Lancet. 2012;379(9816):625-32.

6. Mervel P, Lanta S. Recurrent miscarriage (RM). EMCGynécologie-Obstétrique. 2005;2:278-96.

7. Niang M, Aidibe I. Pregnancy and teen delivery in Senegal: about 302 cases collected in Ninefecha Hospital (Kedougou,Senegal). Journal de la SAGO. 2013;14(2):30-5.

8. Soula O, Carles G, Largeaud M, El Guindi W, Montoya Y. Pregnancy and delivery among adolescents under 15: a study of 181 cases in French Guiana. J Gynecol Obstet Biol Reprod. 2006;35(1):53-61.

9. Mayi-Tsonga S, Obiang PA, Minkobame U, Ngouafo $\mathrm{D}$, Ambounda $\mathrm{N}$, de Souza $\mathrm{MH}$. Introduction of postabortion contraception, prioritizing long-acting reversible contraceptives, in the principal maternity hospital of Gabon. Int $\mathrm{J}$ Gynecol Obstet. 2014;126(1):45-8.

10. Tumasang F, Leke RJ, Aguh V. Expanding the use of manual vacuum aspiration for incomplete abortion in selected health institutions in Yaoundé, Cameroon. Int J Gynecol Obstet. 2014;126(1):28-30.

11. Cissé CT, Faye KG, Moreau JC. First-trimester abortion at University Hospital Center in Dakar, Senegal: utility of manual vacuum aspiration. Med Trop. 2007;67(2):P163-6.

12. World Health Organization. Secure abortion: Technical and strategic Directives for the health care systems, second ed., Geneva; 2013

13. Zaidi S, Yasmin H, Hassan L, Khakwani M, Sami S, Abbas T. Replacement of dilation and curetage/evacuation by manual vacuum aspiration and medical abortion, and the introduction of postabortion contraception in Pakistan. Int $\mathrm{J}$ Gynecol Obstet. 2014;126(Suppl 1):S40-4.

Cite this article as: Marc DJ, Eric B, Ignace $\mathrm{Y}$, Mouhideen O, Gerard O, Privat GY, Simplice A. Post abortion care: experience of the gynecological and obstetrical service of Treichville university hospital center, Abidjan-Cote D'ivoire. Int J Reprod Contracept Obstet Gynecol 2017;6:60-4. 